\title{
Pre-travel Preparedness of International Students Undertaking Electives in a Medical College in Bengaluru City, South India
}

\author{
Bhavya Balasubramanya ${ }^{*}$, Catherin $\mathrm{Nisha}^{2}$, Avita Rose Johnson ${ }^{3}$ \\ ${ }^{1}$ Community Health Department, Rural Unit for Health and Social Affairs, Christian Medical College, Vellore, India \\ ${ }^{2}$ Surveillance Medical Officer, National Polio Surveillance Programme (NPSP), World Health Organization, India \\ ${ }^{3}$ Department of Community Health, St. John's National Academy of Health Sciences, Bangalore, Karnataka State, India
}

Corresponding Author: Bhavya Balasubramanya, MBBS, MD, DNB, Assistant Professor of Community Medicine, Rural Unit for Health and Social Affairs, Christian Medical College, Vellore, Tamil Nadu, India. Tel: +91-9566759397,

Email: bhav2107@cmcvellore.ac.in

Received January 6, 2018; Accepted February 24, 2018; Online Published April 16, 2018

\begin{abstract}
Introduction: The number of foreign travelers arriving in India has shown an exponential increase from 1.2 million in 1981 to 8.03 million in the year 2015, with an annual growth rate of $4.5 \%$. With the influx of internationally mobile students to developing countries such as India comes the responsibility of having to cater to the health needs of these visitors. The current study was undertaken with the objective of assessing how travel prepared the international student travelers were, what gaps existed, and how better to address this issue in the future.

Methods: A cross-sectional study was conducted at a medical college in Bengaluru city of South India during the 6-month period from March to August, 2015. International students doing an elective rotation at the medical college were approached to participate in the study. Written informed consent was obtained from participants, and a 23-item, self-administered questionnaire was distributed to them. Data was entered in EpiData software v3.1 and analyzed using Statistical Package for Social Science v 21.0.

Results: The current study comprised 43 elective students. The mean age of the participants was $24 \pm 2$ years with age ranging from 19-29 years. Females made up the majority $(79.1 \%)$. A majority of the students $(69.8 \%)$ had purchased travel insurance, $62.8 \%$ had consulted a doctor prior to their travel, and $74.4 \%$ had carried a first aid kit during their travel.

Conclusion: The current study highlights the variability in the uptake of pre-travel health consultation, vaccination, and other precautions taken by student travelers. Determining the most appropriate strategies for increasing pre-travel health preparation is the next step in advancing travel medicine research.

Keywords: Travel, Students, Vaccination, India
\end{abstract}

Citation: Balasubramanya B, Nisha C, Johnson AR. Pre-travel preparedness of international students undertaking electives in a medical college in Bengaluru city, South India. Int J Travel Med Glob Health. 2018;6(2):76-80. doi:10.15171/ijtmgh.2018.14.

\section{Introduction}

The globe has shrunk with travel becoming easier and travel between countries being on an all-time high. The number of foreign travelers (FTAs) arriving in India has shown an exponential increase from 1.2 million in 1981 to 8.03 million in the year 2015, with an annual growth rate of $4.5 \%$. India ranks 40th in the world for FTAs. ${ }^{1}$ Of the total foreign tourists arriving in India, 6.4\% landed in Bengaluru city. The top 3 countries accounting for travel into India in the year 2015 were the United States, Bangladesh, and the United Kingdom. ${ }^{1}$ The age group of 25-45 years constituted the major portion of
FTAs with a male predominance. ${ }^{1}$

Around 33000 internationally mobile students were said to have visited India in 2014 for educational purposes, ranking India second globally, just behind China. ${ }^{2}$ Among the states of India, Karnataka ranked first for the number of international students visiting for educational purposes. ${ }^{1}$ Thus, with young individuals embarking upon travel for education, travel preparedness is of utmost importance. It is said that "illness is just a plane ride away." Travel preparedness ${ }^{3}$ as defined by the US Center for Disease Control (CDC) encompasses the following components: visiting a doctor prior to travel,

Copyright (C) 2018 The Author(s). This is an open-access article distributed under the terms of the Creative Commons Attribution License (http:// creativecommons.org/licenses/by/4.0), which permits unrestricted use, distribution, and reproduction in any medium, provided the original work is properly cited. 
purchasing travel insurance, obtaining vaccinations, carrying a copy of medical prescriptions and a travel health kit (containing first aid supplies, medicines, sunscreen and insect repellents), being informed about the country to which travel is planned, and knowing where in the destination country to access healthcare. Along with the influx of internationally mobile students to developing countries such as India comes the responsibility of having to cater to the health needs of these visitors.

A visit to a tropical country like India carries certain risks to travelers, mainly those posed by infectious diseases. The most commonly reported disease amongst travellers is diarrhea, followed by typhoid and mosquito-borne diseases like malaria, dengue fever, and chikungunya. ${ }^{4}$ Travelers are also at risk of rabies, as India has the highest burden of rabies in the world and the highest stray dog population. Risk of wounds and bites from other animals such as cats, monkeys and cattle also exist. ${ }^{4}$ It has been reported that $5.7 \%$ of returning travelers at the Hospital for Tropical Diseases in London had contracted a sexually-transmitted infection (STI) during their most recent travel experience. ${ }^{5}$

This study was done with the objectives of assessing the pre-travel health and vaccination status of international students visiting a medical college in Bengaluru city, South India, ascertaining how prepared the international student travelers were, identifying the gaps, and to determine how better to address this issue in the future.

\section{Methods}

A cross-sectional study was conducted at a medical college in Bengaluru city during the 6-month period from March to August, 2015. A multitude of medical students from various socio-cultural backgrounds visit the institute every year from around the globe, with origins ranging from Canada and the United States in the west to Singapore and Malaysia in the east. An average of 40-50 students rotate at the Department of Community Health, St. John's Medical College, Bengaluru each year. International students doing an elective rotation at the medical college were approached regarding participation in the current study. Written informed consent was obtained from each participant after the study and its future implications were explained to them in detail. Consenting individuals were given a 23-item, self-administered questionnaire to complete. The questionnaire included sections on demography, travel details, travel insurance, pre-travel vaccinations, and details of pre-existing illnesses. The questionnaire was developed by the authors after referring to the International Health Regulations (IHR) and the pre-travel vaccination requirements by the World Health Organization (WHO) and US CDC for travelers to India and face validated by experts in the field of global health and travel medicine.

The sample size for this research project was calculated using the formula $\mathrm{n}=\mathrm{z}^{2 *} \mathrm{P}^{*} \mathrm{Q} / \mathrm{d}^{2}$, where $\mathrm{n}$ is the estimated sample size, $\mathrm{Z}=1.96$ (constant), $\mathrm{P}=17 \%$ (proportion of students who had a pre-travel medical consult among student travellers in Australia), ${ }^{6} \mathrm{Q}=100-\mathrm{p}=83 \%$, and $\mathrm{d}=10 \%$ absolute precision. The estimated sample size was 54 . During the 6-month study period, all foreign elective students who visited the medical college and consented to take part in the study were included. A sample size of $n=43$ was achieved by the end of the study period.

Data was entered in EpiData software v3.1. Statistical analysis was performed using Statistical Package for Social Science (SPSS version 21.0). The data was checked for normality, and then appropriate statistical tests were used. Univariate analysis included frequencies, proportions, mean and standard deviation. For bivariate analysis-correlation, the Pearson's chi-square test and independent samples $t$ test were used. A level of 0.05 was deemed to be statistically significant at a $95 \% \mathrm{CI}$.

\section{Results}

The current study comprised 43 elective students who visited the medical college in Bengaluru for a rotatory observership during the period of March to August 2015. The mean age of the participants was $24 \pm 2$ years with ages ranging from 19 to 29 years. Females made up the majority at $79.1 \%$. The country profile of the students is given in Table 1 . The average duration of stay was $44 \pm 26$ days with stays ranging from 25 to 124 days.

The study assessed travel preparedness by looking into the domains of travel insurance, pre-travel physician consult, and pre-travel vaccinations as recommended by the IHR 2005 for a visit to the Indian sub-continent.

\section{Travel Insurance}

A majority of the students (69.8\%) had purchased travel insurance to cover the period of travel. The cost of insurance ranged from $\$ 5$ to $\$ 150$ with an average cost of $\$ 57$. There was a statistically significant association between continent of residence and purchase of travel insurance, with a higher proportion of individuals from Europe and North America having insured their travel vs those from Asia $\left(\chi^{2}=17.99\right.$, $P=0.012)$. There was no difference between genders $\left(\chi^{2}\right.$ $=3.46, P=0.063)$, however an Independent samples $t$ test (Table 2) showed higher mean age to be significantly associated with purchase of travel insurance $(P=0.046)$.

\section{Pre-travel Physician Consult}

Among the study participants, $62.8 \%$ had consulted a doctor prior to their travel. The rate of pre-travel physician consult was not observed to be different among various continents or across gender groups; however, an independent samples $t$ test (Table 2) revealed higher mean age to be significantly associated with doctor consult $(P=0.046)$. Sixteen percent of participants reported having a pre-existing illness, $4.7 \%$ had carried a copy of their medical records, whereas none of the

Table 1. Country Profile of Study Participants $(n=43)$

\begin{tabular}{ll}
\hline Country (Continent) & No. $(\%)$ \\
\hline USA (North America) & $6(14.1)$ \\
UK (Europe) & $8(18.6)$ \\
Sweden (Europe) & $14(32.6)$ \\
Germany (Europe) & $6(14.1)$ \\
United Arab Emirates (Asia) & $5(11.6)$ \\
\hline
\end{tabular}


Table 2. Independent Samples $T$ Test showing Age-Related Outcomes $(n=43)$

\begin{tabular}{lll}
\hline Travel Insurance Purchased & $\begin{array}{l}\text { Age }(\mathbf{y}) \\
\text { Mean } \pm \text { SD }\end{array}$ & $\boldsymbol{P}$ \\
\hline Yes & $24.40 \pm 2.06$ & 0.050 \\
No & $23.00 \pm 2.16$ & \\
Pre-travel Physician Consult & & \\
Yes & $24.48 \pm 1.92$ & \\
No & $23.12 \pm 2.33$ & 0.046 \\
\hline
\end{tabular}

participants carried a prescription for medications they took regularly. Pre-existing illnesses $(n=6)$ included bronchial asthma, eczema, migraine, type 1 diabetes, psoriasis, and thyroiditis. When asked about where they would seek medical care if they fell sick during their travel to India, the majority replied that they would go to a private hospital or clinic (48.8\%) or prefer self-medication (44.2\%).

\section{Pre-travel Vaccination Status}

When asked about having received a vaccine prior to travel for the purpose of traveling to India (as recommended by the CDC and WHO), 86\% replied that they had received a vaccine. Table 3 shows the vaccines received by the study participants prior to travel.

The pre-travel vaccination status showed a statistically significant association with the continent of Europe having the highest proportion of vaccinated travellers as compared with North America and Asia $\left(\chi^{2}=17.2, P=0.016\right)$.

\section{Travel Preparedness}

The International Health Regulations specify what needs to be carried as part of a traveler's first aid kit (Table 4). The majority of student travelers $(74.4 \%)$ had carried a first aid kit during their travel to South India. The most commonly carried contents were a thermometer $(72.1 \%)$, sunscreen lotion $(67.4 \%)$, insect repellent (60.5\%), antiseptic solution (53.5\%), and ear plugs (44.2\%). On being asked whether they had carried any medicines on their travel, 95.3\% answered in the affirmative, the most common medications being paracetamol (81.4\%), anti-diarrheals (58.1\%), antibiotics (41.9\%), and antihistamines (41.9\%). Only 34.9\% reported having carried an oral rehydration salt sachet with them. There was no significant association between carrying a first aid kit and gender, country, or presence of pre-existing illness.

During their travels, about one fifth of the participants (20.9\%) had planned to take up activities like trekking (14\%) and water sports (6.9\%). Participants were asked to rate their current health status on a scale of 0 to 10 ( 0 being poor and 10 being excellent). The mean self-rating of health was 9.58 \pm 0.6 , with a range of 8 to 10 , which shows that apparently healthy individuals undertook travel.

Participants were asked to list the top three health issues they may expect to face during their travels. The most commonly stated issues were diarrhoea (60.5\%), tuberculosis (51.2\%), typhoid (25.6\%), and dengue fever (20.9\%).

\section{Discussion}

Travel preparedness involves an awareness of health risks at the
Table 3. Vaccines Received by Participants Prior to Travel $(n=43)$

\begin{tabular}{lc}
\hline Vaccine & $\begin{array}{c}\text { Received Vaccine } \\
\text { No. }(\%)\end{array}$ \\
\hline Typhoid & $33(76.7)$ \\
Tetanus toxoid & $31(72.1)$ \\
Hepatitis A & $25(58.1)$ \\
Hepatitis B & $23(53.5)$ \\
Polio & $19(44.2)$ \\
Varicella & $11(25.6)$ \\
Yellow fever & $8(18.6)$ \\
Japanese encephalitis & $8(18.6)$ \\
Anti-rabies & $6(14)$ \\
Influenza & $5(11.6)$ \\
\hline
\end{tabular}

Table 4. First Aid Kit and Medications Carried by Travellers $(n=43)$

\begin{tabular}{lc}
\hline First Aid Kit Contents & No. (\%) \\
\hline Thermometer & $31(72.1)$ \\
Sunscreen & $29(67.4)$ \\
Insect repellent & $26(60.5)$ \\
Antiseptic solution & $23(53.5)$ \\
Earplugs & $19(44.2)$ \\
Bandages & $17(39.5)$ \\
Tape & $15(34.9)$ \\
Oral rehydration salt & $15(34.9)$ \\
Scissors & $11(25.6)$ \\
Eye drops & $10(23.3)$ \\
Safety pin & $7(16.3)$ \\
Medications Carried & \\
Paracetamol/NSAID & $35(81.4)$ \\
Anti-diarrhoeal & $25(58.1)$ \\
Antibiotics & $18(41.9)$ \\
Anti-histamine & $18(41.9)$ \\
Anti-malarial & $12(27.9)$ \\
Antifungal & $2(4.7)$ \\
\hline
\end{tabular}

proposed destination and steps taken to mitigate those health risks. This includes pre-travel consultation and vaccination as well as the acquisition of a list of required medications and medical supplies. The current study was undertaken with the objective of documenting the pre-travel preparedness of international overseas medical students visiting a medical college in Bengaluru with the ultimate aim of identifying and addressing the gaps in their preparedness. Numerous surveys have shown that travelers considerably underestimate the risks associated with travel to developing countries and subsequently lack preparation to avoid infectious disease risks. ${ }^{7-14}$ This is especially true for younger travelers, who are disproportionately represented in studies assessing infectious symptoms post-travel. ${ }^{6,15-23}$ Younger travelers are at greater risk of contracting infectious diseases which have been attributed to a higher susceptibility, particularly to vaccine-preventable diseases and greater exposure due to increased risk-taking behaviors and travel to high-risk destinations. ${ }^{24}$

About two thirds of the study participants (62.8\%) had consulted a doctor prior to their travel. Pre-travel health 
seeking practices are influenced by many factors including traveler demographic characteristics, reasons for travel, and previous travel experience. Few studies investigate differences in health-seeking norms by nationality. ${ }^{25}$ Health seeking practices are likely to differ by nationality due to differences in country-specific healthcare systems, such as national vaccination programs and travel health facilities as well as promotional activities undertaken by health departments and private travel medicine groups. However, the current study showed that uptake of pre-travel health advice from a health professional did not differ based on region of residence.

Data on the vaccination status of participants showed that most of the visiting international students lacked protection against potentially fatal diseases for which the WHO recommends vaccination. This data is consistent with the findings of other authors and calls for action to promote vaccination of unprotected individuals at risk of exposure. ${ }^{26,27}$ Pre-travel vaccination requires not only knowledge of which diseases are endemic in the destination country, but also time, as most vaccines take about 4 weeks to become effective and some even require more than one dose. The required timeframe needs to be factored in when making travel plans. For example, vaccines like hepatitis A and hepatitis B have been recommended prior to travel to India by the US CDC. ${ }^{4}$ These vaccines require a longer time for the entire schedule to be administered. ${ }^{4}$

A study among international travellers to Sub-Sahara Africa by Pavli et a ${ }^{28}$ showed lower rates of vaccination for typhoid, hepatitis A, and tetanus toxoid than seen in the present study, in which vaccination rates were reported to be $76.7 \%, 72.1 \%$, and $58.1 \%$, respectively (Table 3 ). This may be explained by the origin of travelers from the United States, United Kingdom, and Europe where travel clinics are well established and travelers are better informed.

The CDC strongly recommends pre-exposure prophylaxis vaccination for rabies for people traveling to India. ${ }^{4}$ Not all the student travelers in this study $(37,86 \%)$ were protected against this important disease.

Dengue fever, chikungunya, and malaria which are spread by mosquito bites and Kyasanur Forest disease spread by tick bites are endemic in the state of Karnataka, India. Only about two-thirds of the visitors in this study had carried insect repellents with them. Emphasis must be placed on the use of personal protective equipment and mosquito repellent creams and coils while visiting this part of India. Malaria chemoprophylaxis is not a must for travel to Bengaluru city.

The majority of the student travelers in this study (74.4\%) carried a first aid kit and necessary medications; however, only $34.9 \%$ reported carrying an oral rehydration salt (ORS) sachet. This is remarkable, considering most student travelers in the present study visited Bengaluru during the summer and monsoon seasons. ORS has been recommended by the CDC to be carried by travelers to prevent dehydration from travelers' diarrhea. ${ }^{4}$ It is important that this recommendation be reinforced when communicating with visiting students prior to their travel.

As a result of this study, the need is felt for a document covering pre-travel health advice, suggested vaccinations,

\section{Research Highlights}

What Is Already Known?

India has the second largest influx of internationally mobile student travellers.

\section{What This Study Adds?}

- A novel study done among student travellers visiting a medical college in a middle income country like India.

- There exist large gaps in uptake of pre-travel consultation, vaccination and travel insurance purchase.

- Pre-travel preparedness is variable, and largely depends on the country of origin and age of the student traveller.

and a list of required medicines for travel to India, Bengaluru in particular, which should be shared with international students as soon as they apply for an elective posting in this location. Since students usually apply 3-6 months in advance, this would give them an opportunity to be better prepared to mitigate health risks during their travel and stay in Bengaluru.

A limitation of this study was that the estimated sample size could not be achieved, because the required number of students did not rotate at the college during the short study period of 6 months; hence, corroborative inferences cannot be made. This research can be considered as a pilot study, paving the way for a larger study in the future. Pre-travel vaccination was self-reported by the students. A better measure would have been to verify this information by looking at their vaccination cards or measuring serum antibody levels. The generalizability of the current results is limited as only a select group of students who had visited one medical college in Bengaluru were studied.

\section{Conclusion}

The current study highlights the variability in the uptake of pretravel health consultation, vaccination, and other precautions. Limited data is available on young travelers despite high international student numbers and a high likelihood of travel in this age group. It is known that young students have a high likelihood of international travel. These students are not being targeted appropriately to ensure adequate protection from a lifetime of travel health risks. There is a need to improve vaccination and health-seeking behavior in this highly mobile young adult population. Determining the most appropriate strategies for increasing pre-travel health preparation, particularly for vaccine-preventable diseases in travelers, is the next stage in advancing travel medicine research.

\section{Authors' Contributions}

All authors have been involved in the concept, study design, data collection, analysis, manuscript writing and review of this study.

\section{Conflict of Interest Disclosures}

The authors declare that there is no conflict of interest. 


\section{Ethical Approval}

This study was done as part of the on-going overseas student elective program at St. John's Medical College, Bengaluru. Permission to conduct the study was obtained from the Department of Community Health. Informed written consent was obtained from all participants, and confidentiality was maintained.

\section{Funding/Support}

None.

\section{References}

1. Indian Tourism Statistics. Market Research Division. Ministry of Tourism, Government of India; 2015.

2. Status of International students in India for higher education. Government of India and UNESCO; 2014.

3. Travel Preparedness - Prepare for everywhere. CDC. https://www. cdc.gov/phpr/documents/pre-infographictravelprep.pdf. Accessed August 8, 2017.

4. CDC Yellow Book: Health information for International Travel 2018. https://wwwnc.cdc.gov/travel/yellowbook/2018/selectdestinations/india.

5. Hawkes S, Hart GJ, Johnson AM, et al. Risk behaviour and HIV prevalence in international travellers. AIDS. 1994;8(2):247-252. doi:10.1097/00002030-199402000-00013.

6. Heywood AE, Watkins RE, lamsirithaworn S, Nilvarangkul K, Maclntyre CR. A cross-sectional study of pre-travel health-seeking practices among travelers departing Sydney and Bangkok airports. BMC Public Health. 2012;12:321. doi:10.1186/1471-2458-12321.

7. Laver SM, Wetzels J, Behrens RH. Knowledge of malaria, risk perception, and compliance with prophylaxis and personal and environmental preventive measures in travelers exiting Zimbabwe from Harare and Victoria Falls International airport. J Travel Med. 2001;8(6):298-303. doi:10.2310/7060.2001.23975.

8. Van Herck K, Van Damme P, Castelli F, et al. Knowledge, attitudes and practices in travel-related infectious diseases: the European airport survey. J Travel Med. 2004;11(1):3-8. doi:10.2310/7060.2004.13609.

9. LaRocque RC, Rao SR, Tsibris A, et al. Pre-travel health adviceseeking behavior among US international travelers departing from Boston Logan International Airport. J Travel Med. 2010;17(6):387391. doi:10.1111/j.1708-8305.2010.00457.x.

10. Lopez-Velez R, Bayas JM. Spanish travelers to high-risk areas in the tropics: airport survey of travel health knowledge, attitudes, and practices in vaccination and malaria prevention. J Travel Med. 2007;14(5):297-305. doi:10.1111/j.1708-8305.2007.00142.x.

11. Wilder-Smith A, Khairullah NS, Song JH, Chen CY, Torresi J. Travel health knowledge, attitudes and practices among Australasian travelers. J Travel Med. 2004;11(1):9-15. doi:10.2310/7060.2004.13600.

12. Hamer DH, Connor BA. Travel health knowledge, attitudes and practices among United States travelers. J Travel Med. 2004;11(1):23-26. doi:10.2310/7060.2004.13577.

13. Toovey S, Jamieson A, Holloway M. Travelers' knowledge, attitudes and practices on the prevention of infectious diseases: results from a study at Johannesburg International Airport. J Travel Med. 2004;11(1):16-22. doi:10.2310/7060.2004.13587.

14. Ahlm C, Lundberg S, Fesse K, Wistrom J. Health problems and self-medication among Swedish travellers. Scand J Infect Dis. 1994;26(6):711-717. doi:10.3109/00365549409008640.

15. Fleck $S$, Jager $H$, Zeeb $H$. Travel and health status: a survey followup study. Eur J Public Health. 2006;16(1):96-100. doi:10.1093/ eurpub/cki144.

16. Redman CA, Maclennan A, Wilson E, Walker E. Diarrhea and respiratory symptoms among travelers to Asia, Africa, and South and Central America from Scotland. J Travel Med. 2006;13(4):203211. doi:10.1111/j.1708-8305.2006.00046.x.

17. Rack J, Wichmann O, Kamara B, et al. Risk and spectrum of diseases in travelers to popular tourist destinations. J Travel Med. 2005;12(5):248-253. doi:10.2310/7060.2005.12502.

18. Winer L, Alkan M. Incidence and precipitating factors of morbidity among Israeli travelers abroad. J Travel Med. 2002;9(5):227-232. doi:10.2310/7060.2002.24202.

19. Abdullah AS, McGhee SM, Hedley AJ. Health risks during travel: a population-based study amongst the Hong Kong Chinese. Ann Trop Med Parasitol. 2001;95(1):105-110. doi:10.1080/00034983 .2001.11813620.

20. Cossar JH, Reid D, Fallon RJ, et al. A cumulative review of studies on travellers, their experience of illness and the implications of these findings. J Infect. 1990;21(1):27-42. doi:10.1016/01634453(90)90600-D.

21. Cabada MM, Maldonado F, Mozo K, Seas C, Gotuzzo E. Selfreported health problems among travelers visiting Cuzco: a Peruvian Airport survey. Travel Med Infect Dis. 2009;7(1):25-29. doi:10.1016/j.tmaid.2008.09.005.

22. Steffen R, Rickenbach $M$, Wilhelm U, Helminger A, Schar $M$. Health problems after travel to developing countries. J Infect Dis. 1987;156(1):84-91. doi:10.1093/infdis/156.1.84.

23. Pizam A, Jeong GH, Reichel A, et al. The Relationship between Risk-Taking, Sensation-Seeking, and the Tourist Behavior of Young Adults: A Cross-Cultural Study. J Travel Res. 2004;42(3):251-260. doi:10.1177/0047287503258837.

24. Heywood AE, Zhang M, Maclntyre CR, Seale H. Travel risk behaviours and uptake of pre-travel health preventions by university students in Australia. BMC Infect Dis. 2012;12:43. doi:10.1186/1471-2334-12-43.

25. Thanassi W, Weiss E. Travel related emergencies: immunizations and travel. Emerg Med Clin North Am.1997;15:43-70. doi:10.1016/S0733-8627(05)70285-6.

26. Scoville SL, Bryan JP, Tribble D, et al. Epidemiology, preventive services, and illnesses of international travelers. Mil Med. 1997;162(3):172-178. doi:10.1093/milmed/162.3.172.

27. Schunk M, Wachinger W, Nothdurft HD. Vaccination status and prophylactic measures of travelers from Germany to subtropical and tropical areas: results of an airport survey. J Travel Med. 2001;8(5):260-262. doi:10.2310/7060.2001.24031.

28. Pavli A, Smeti P, Antoniadou F, Katerelos P, Maltezou HC. Vaccinations of international travellers from Greece to SubSaharan Africa. Int J Travel Med Glob Health. 2017;5(2):46-52. doi:10.15171/ijtmgh.2017.10. 